\title{
POSTERIORI OPTIMIZATION OF ACTIVE GEODETIC MONITORING NETWORKS
}

\author{
Kornyliy Tretyak, Igor Savchyn \\ Institute of Geodesy, National University Lviv Polytechnic, \\ Lviv, Ukraine
}

\begin{abstract}
This paper presents developed method of a posteriori optimization of measurement results of active geodesic monitoring networks with taking into account the parameters of accuracy and reliability. Filtering the measurement results of active geodetic monitoring networks is in out of order exclusion vectors with maximum corrections, which is determined from successive iterations of network adjustment. After each iteration it's determined the mean square error of unit weight and the parameter of network reliability. Sifting vectors with maximal errors leads to accuracy improving and reliability deterioration of network. Using entropy approach is defined group of vectors in which the value of accuracy and reliability is optimal. Using the developed method performed a posteriori optimization of active precision geodesic monitoring network of the Dnieper, Dniester and Kanev HPP. The represented method can also be used for the optimization of any active geodesic monitoring networks with large quantity of redundant measurements.
\end{abstract}

Keywords: active geodetic monitoring network, parameter of reliability, posterior optimization of geodetic network, large redundancy

\section{Introduction}

In a period of rapid development of automated systems, a posteriori optimization of the results of geodetic measurements of active monitoring networks remains a pressing question. Those types of networks are designed for installing a large number of GNSS receivers that monitor objects in real time (Craenenbroeck, 2012; Rizos et al., 2010; Stempfhuber \& Alberding, 2012). The productivity of active geodetic monitoring networks depends on the configuration of the measured vectors (Even-Tzur, 2002). Some measurements in such networks are distorted by errors that exceed the general background of the errors of all the measurements. These measurements significantly decrease accuracy. In the study (Tretyak, 2003), the 
author claims that the detection and elimination of such measurements will give the opportunity to significantly improve the accuracy of the results of network adjustment. However, the author does not specify how the filtering of part of the measurement distorted by large errors will affect the reliability of the network.

Under network reliability the accuracy of determining the true displacements and deformations of the object is understood, namely the percentage ratio between the number of inaccurate series of measurements and the total number of series of measurements. Reliable series of measurements based on the results of the network adjustment should meet the following conditions (Tretyak \& Savchyn, 2013a):

1 ) if the displacement of the points is absent, the influence of measurement errors should not be interpreted as a displacement of points;

2 ) if the displacement of the points is in the framework of the geometric accuracy of the network, it must be interpreted as the effect of measurement error;

3 ) if the displacement of the points is bigger than the geometric accuracy of measurements in the network, the displacement should not be interpreted as the effect of measurement error in the network.

Article (Knight et al., 2010) presents a method for quantitative calculation of the parameter of reliability. The problem of optimization of geodetic constructions using a parameter of reliability is discussed in publications of Rodionova (2006), Tretyak \& Savchyn (2013a, b) and Proszynski (2010). In the article (Rodionova, 2004) the method of calculating the necessary number of measurements to achieve high reliability of geodetic networks is shown.

However, in the published articles the problem of posteriori optimization of an active geodetic monitoring networks the parameters of accuracy and reliability are not considered, therefore research in this area is important.

\subsection{Development of posteriori optimization methods of active geodetic monitoring networks}

Development of posteriori optimization methods was performed by the method of mathematical modeling based on GNSS network, which consists of 16 points (Fig. 1). Two network points are considered to be base points.

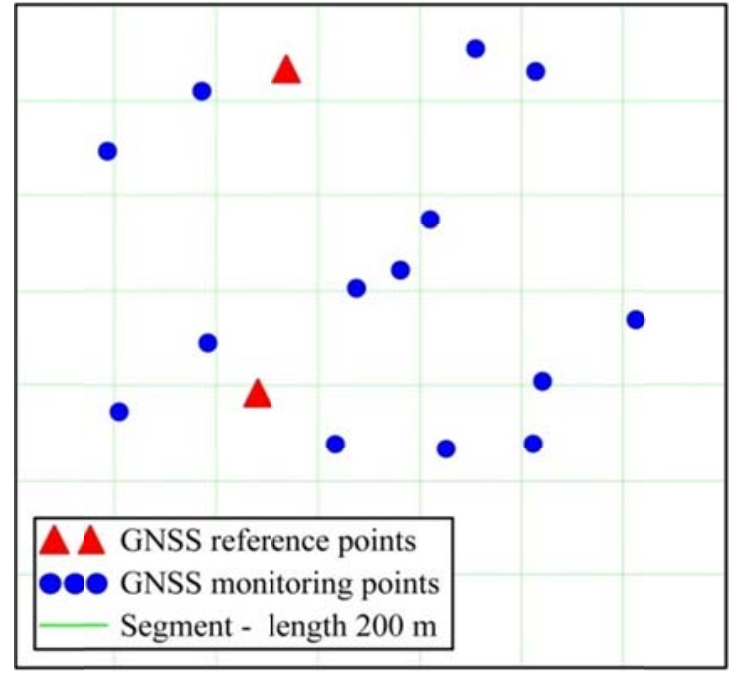

Fig. 1. The scheme of the location points of a model active geodetic monitoring network 
The presented network the measurements of all vectors are modeled, that is, their number is equal, $t_{\max }=\frac{n(n-1)}{2}, n-$ the number of network points. The errors of vectors' measurement are modelled within the mean square error of measurement of the lengths of vectors $m_{v e c}$. During the modelling the normal distribution law of errors is applied. Figure 2 presents the histogram of distribution of model measurements' errors $\Delta$.

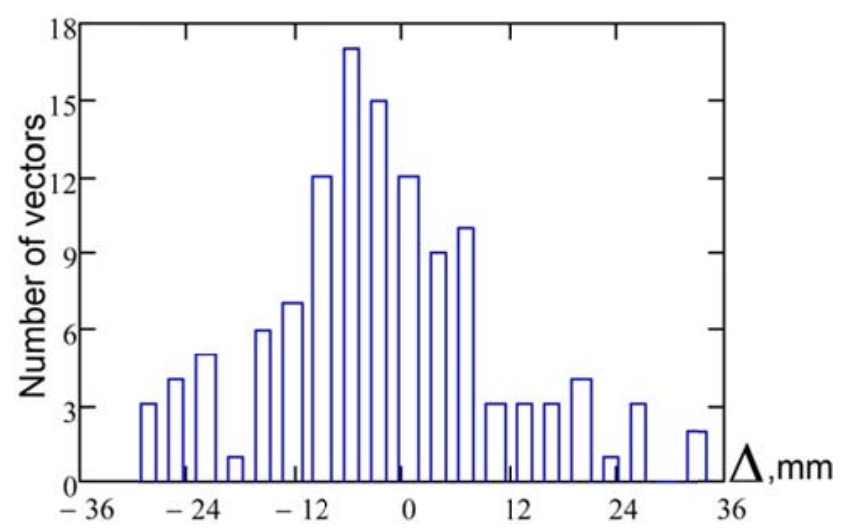

Fig. 2. Histogram of distribution of model measurements' errors

Analyzing presented histogram, it may be noticed that some of the measurements in the network have errors that exceed the cumulative background of all errors. A similar graph is observed during the actual measurements, due to the peculiarities of the object, multichannel signal and poor visibility of satellites.

Measurements' filtering that have maximum errors is based on alternately withdrawal of vectors with the maximum corrections $v$, which are determined from successive iterations of the network adjustment by the following dependence (that it relates to a standardized system of equation):

$$
v=A \cdot \Delta x+L
$$

where: $A$ - is the coefficients' matrix of the formulae of corrections, $\Delta x$ - corrections to the approximate value of the unknown parameters, which are determined with the help of network adjustment, $L$ - matrix-vector of the absolute term.

After each iteration parameter of the network reliability (Tretyak \& Savchyn, $2013 b)$ and the mean square error of weight unit are defined with the help of the following formulae:

$$
\begin{gathered}
P_{\text {adjust. }}=(25,278+14,489 \cdot \ln (r)) \cdot\left(D^{n o r m}\right)^{(-0,071+0,014 \ln (r))} \\
\mu_{\text {adjust. }}=\sqrt{\frac{\sum v^{2}}{r}}
\end{gathered}
$$

where: $r$ - is the number of redundant measurements in the network, $D^{n o r m}=\sqrt[n-2]{D}$ - normalized determinant ( $D$ - determinant of the covariance matrix). 
When the minimum number of vectors needed for adjustment will remain in the network $t_{\min }=\frac{3 n-2}{2}\left(t_{\min }\right.$ - rounded up to a whole $)$ the process of withdrawal of vectors should be completed. When the number of vectors is less than $t_{\min }$, then at least one item is determined uncontrollably.

On the basis of the performed modeling a graph of accuracy and reliability of the network at the consequent exclusion of vectors with the maximum errors is built. The following graph is presented as figure 3 .

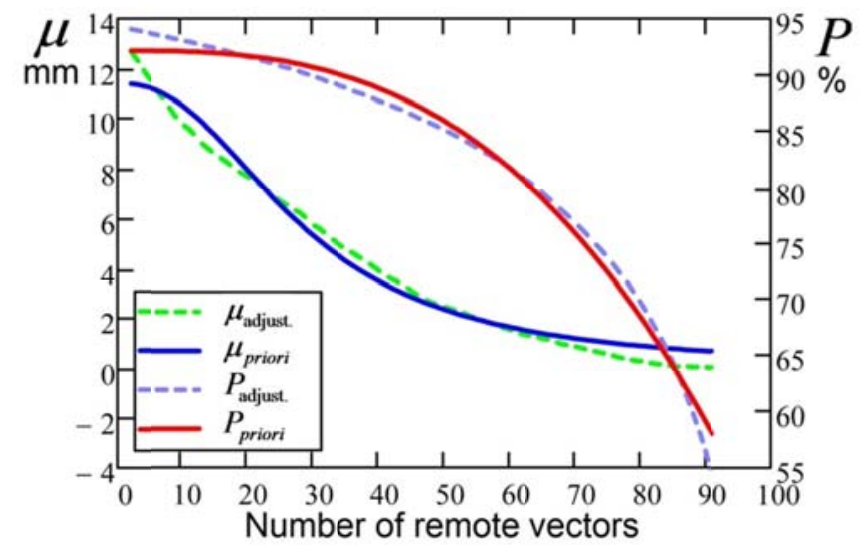

Fig. 3. The change of accuracy and reliability at the consequent exclusion of vectors with the maximum errors

At the beginning of the vectors' elimination value $\mu_{\text {adjust. }}$ decreases faster than later. It is connected with the immediate withdrawal of measurements, which contain larger errors than all the rest (Tretyak, 2003). At the end of the vectors' elimination process, the change $\mu_{\text {adjust. }}$ is minimal, that is explained by the withdrawal of vectors with minimal errors, which practically do not affect the result of the balancing.

The value of network reliability $P_{\text {adjust. }}$ at the beginning of the vectors' elimination is decreasing very slowly, that is due to the large amount of redundant measurements. At the end of the elimination process reliability decreases very quickly, this is due to the relatively small number of redundant measurements. Therefore, increases the likelihood that the treatment of the particular series of measurements of withdrawal of vectors with the maximum corrections $v$, will not be vectors with the maximum measurement errors $\Delta$.

Vectors' elimination with the maximum errors leads to improved accuracy and deteriorated reliability. The optimal group of vectors, in which the ratio of accuracy and reliability will be optimal, has to be determined.

To establish a functional dependence between $\mu, P$ and $k$ ( $k$ - the iteration number or the number of the withdrawn vectors) the approximation of curves $\mu_{\text {adjust. }}$ and $P_{\text {adjust. }}$ (see Fig. 3 ) should be performed by using the features that describe them the best:

$$
\mu_{\text {priori }}(k)=\frac{a_{\mu}}{b_{\mu}+k^{c_{\mu}}}
$$




$$
P_{\text {priori }}(k)=a_{P} \cdot k^{b_{P}}+c_{P} \cdot k^{d_{P}}+e_{P}
$$

where: $a_{\mu}, b_{\mu}, c_{\mu}, a_{P}, b_{P}, c_{P}, d_{P}, e_{P}$ - unknown coefficients, which are determined according to the results of approximation. The approximation of curves using the method of least squares should be conducted. In our case we get the following values of the unknown coefficients:

$$
\begin{array}{cccc}
a_{\mu}=3.047 \cdot 10^{4} & b_{\mu}=2.663 \cdot 10^{3} & c_{\mu}=2.361 & e_{P}=92.180 \\
a_{P}=-9.817 \cdot 10^{-5} & b_{P}=2.828 & c_{P}=-92.180 & d_{P}=-42.779
\end{array}
$$

For the presented case of the approximation accuracy of functions $\mu=\mu(k)$ and $P=P(k)$, is respectively $3.81 \%$ and $1.09 \%$.

The parameters $\mu$ and $P$ have different physical nature and metrics, therefore, to bring them into one system normalized derivatives should be utilized:

$$
\begin{gathered}
\left|\frac{d \mu_{\text {priori }}(k)}{\mu_{\text {priori }}(k) d k}\right|=-\frac{k^{c_{\mu}-1} \cdot c_{\mu}}{k^{c_{\mu}}+b_{\mu}} \\
\left|\frac{d P_{\text {priori }}(k)}{P_{\text {priori }}(k) d k}\right|=\frac{k^{b_{P}-1} \cdot a_{P} \cdot b_{P}+k^{d_{P}-1} \cdot c_{P} \cdot d_{P}}{k^{b_{P}} \cdot a_{P}+k^{d_{P}} \cdot c_{P}+e_{P}}
\end{gathered}
$$

To determine the boundaries of the vectors' optimal number which have to be deleted to ensure the best correlation of the accuracy and reliability of the network the formulae for the second of normalized derivatives are shown below:

$$
\begin{gathered}
\left|\frac{d^{2} \mu_{\text {priori }}(k)}{\mu_{\text {pripri }}(k) d k^{2}}\right|=\frac{2 \cdot k^{2 \cdot c_{\mu}-2} \cdot a_{\mu} \cdot c_{\mu}{ }^{2}}{a_{\mu} \cdot\left(k^{c_{\mu}}+b_{\mu}\right)^{2}}-\frac{k^{c_{\mu}-2} \cdot\left(c_{\mu}-1\right) a_{\mu} \cdot c_{\mu}}{a_{\mu} \cdot\left(k^{c_{\mu}}+b_{\mu}\right)} \\
\left|\frac{d^{2} P_{\text {priori }}(k)}{P_{\text {priori }}(k) d k^{2}}\right|=\frac{k^{b_{P}-2} \cdot\left(b_{P}-1\right) \cdot a_{P} \cdot b_{P}}{k^{b_{P}} \cdot a_{P}+k^{d_{P}} \cdot c_{P}+e_{P}}+\frac{k^{d_{P}-2} \cdot\left(d_{P}-1\right) \cdot c_{P} \cdot d_{P}}{k^{b_{P}} \cdot a_{P}+k^{d_{P}} \cdot c_{P}+e_{P}}
\end{gathered}
$$

A graph showing the change of values of the second normalized derivatives of functions $\mu(k)$ and $P(k)$ is presented on figure 4 .

Analyzing the presented graph it can be concluded that the maximum of the function (9) (18 remote vectors) is the margin after which the decrease of the parameter $\mu_{\text {adjust. }}$ is getting slower, so the vectors that are displayed before the margin must be remote, because those are the measurements with the maximum errors that affect the accuracy. The maximum of the function (10) (37 remote vectors) is the margin after which the value of network reliability $P_{\text {adjust. }}$ starts to decrease sharply, so removing the measurements after this limit is not desirable. Therefore, 
the optimal number of dimensions that has to be remote to ensure maximum accuracy and reliability of results is between the maximums functions (9) and (10).

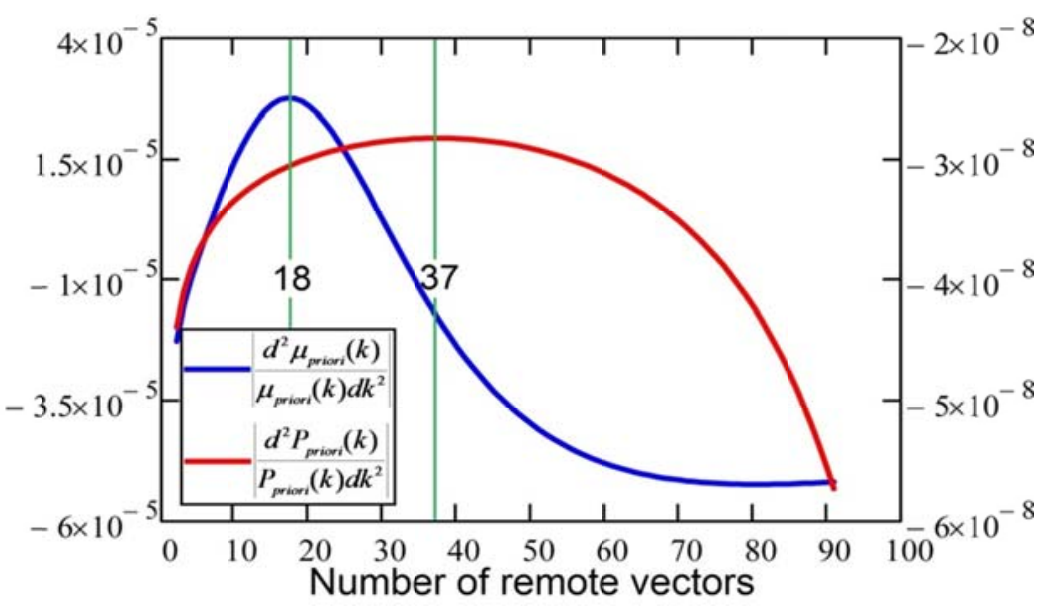

Fig. 4. The change of values of the second normalized deriviatives of functions $\mu(k)$ and $P(k)$

At this interval (18 - 37 remote vectors) network adjustment will give optimal results, however some will have better accuracy and worse relialbility, and others, vice versa, better reliability, but worse accuracy.

To establish the exact number of measurements that has to be remote to ensure the best value for the accuracy and reliability of the network the entropic approach was used. The informational entropy is understood as a measure of uncertainty or unpredictability of information. In the absence of information loss, numerically equal to the amount of information per symbol message that is sent. In other words, this is a measure, which shows the information content of the combined data. According to the theory of information and the optimization of the geodetic networks, the information entropy of the geodesic network is the total entropy of accuracy and reliability measurements (Tretyak, 1993, 2003):

$$
H_{m}(k)=H_{\mu}(k)+H_{P}(k)
$$

For presented model of network and model of the measurement results, informational entropy can be written as:

$$
H_{m}(k)=-\ln [\mu(k)]-\ln [P(k)]
$$

Graph shows the dependence of the entropy values of geodesic networks on the number of remote vectors (Fig. 5.).

Analyzing the presented graph, it can be seen that all the major values of the function $H_{m}(k)$ are within the optimal group of vectors, that is, between 18 and 37 remote vectors. Therefore, we can conclude that at the maximum of function $H_{m}(k)$ (31 remote vectors) the adjustment of networks will provide the best value for accuracy and reliability. 


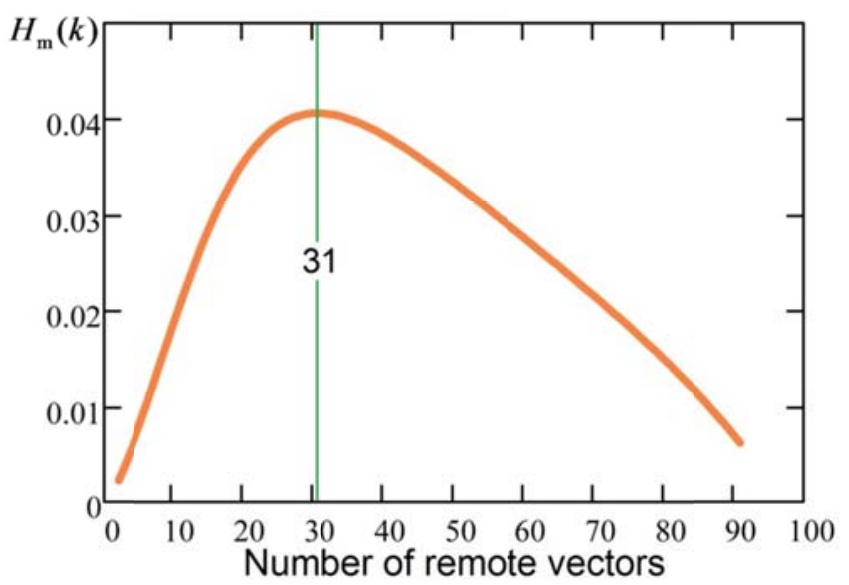

Fig. 5. The change of the geodesic networks entropy $H_{m}(k)$

Experimental research of various model networks proved that these patterns are characteristic for networks of any configuration and reliability. Therefore, it can be concluded that presented the method can be applied for optimization of any active geodetic monitoring networks with a large number of redundant measurements.

\subsection{A posteriori optimization of active geodetic monitoring networks of the Dnieper, Dniester and Kanev HPP}

Using the developed method a posteriori optimization of the results of geodetic measurements of active monitoring networks on Dnieper, Dniester and Kanev HPP taking into account parameters of accuracy and reliability was performed. The network of the Dnieper HPP consists of 19 points (Fig. 6a), and a networks of Kanev and Dniester HPP consists of 14 points (Fig. 6b,c). In each of these networks 2 points are taken as base points.

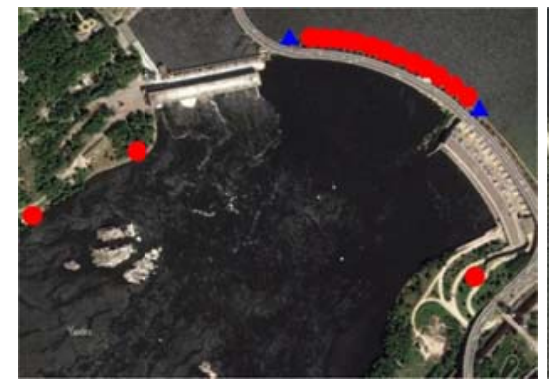

a)

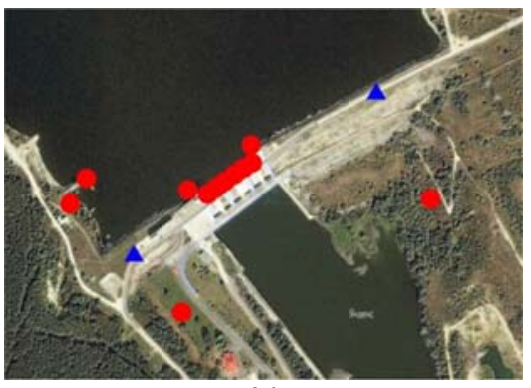

b)

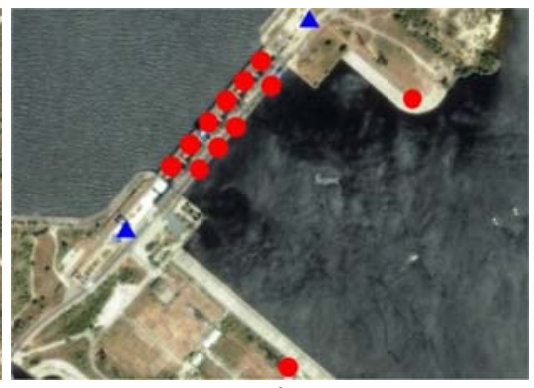

c)

Fig. 6. Placement of active geodetic monitoring networks

(a) Dnieper HPP; b) Dniester HPP; c) Kanev HPP)

GNSS receivers that within a specified period of time at each given epoch perform a series of geodetic measurements have been installed at all points of presented networks. One cycle of observations is understood as a series of measurements. On the basis of these measurements the location of all items of geodetic network in a given coordinate system is determined.

Several cycles of observations made with the help of GNSS receivers of automated monitoring stations on the network (see Fig. 6) was processed. Used to process two hours files of observations (RINEX-file) were used for processing. 
As an example, the results of processing of one cycle of observations in each of the networks are shown. It should be noted that processing of other two hours files of measurements gave practically identical results.

According to the developed method, the value of the accuracy and reliability while removing of vectors with the maximum errors vary according to the functions (4) and (5), therefore completing the approximation with the help of the least squares method in our case, the value of the unknown coefficients will be determined (tab. 1). The accuracy of approximation of functions varies within $1-5 \%$.

Table 1. The values of the coefficients for functions (4) and (5)

\begin{tabular}{|c|c|c|c|c|c|c|c|c|}
\hline \multirow{2}{*}{ HPP } & \multicolumn{3}{|c|}{$\mu_{\text {priori }}(k)$} & \multicolumn{5}{c|}{$P_{\text {priori }}(k)$} \\
\cline { 2 - 9 } & $a_{\mu}$ & $b_{\mu}$ & $c_{\mu}$ & $a_{P}$ & $b_{P}$ & $c_{P}$ & $d_{P}$ & $e_{P}$ \\
\hline Dnieper & $2.89 \cdot 10^{4}$ & $3.39 \cdot 10^{3}$ & 2.166 & $-3.56 \cdot 10^{-5}$ & 2.816 & -91.440 & -43.058 & 91.440 \\
\hline Dniester & $1.21 \cdot 10^{4}$ & $1.13 \cdot 10^{3}$ & 2.265 & $-5.82 \cdot 10^{-4}$ & 2.608 & -91.667 & $-8.8 \cdot 10^{-5}$ & 91.668 \\
\hline Kanev & $1.77 \cdot 10^{4}$ & $1.92 \cdot 10^{3}$ & 2.431 & $-4.67 \cdot 10^{-4}$ & 2.658 & -91.856 & -35.861 & 91.857 \\
\hline
\end{tabular}

Since the presented networks have different geometrical shape and different dimensions, the values of the obtained coefficients are different.

Values of the second normalized derived functions $\mu(k)$ and $P(k)$ were calculated in order to determine the boundaries of the optimal number of vectors to be removed to ensure the best value for the accuracy and reliability of data networks. Functions (9) and (10) were used for calculations, as well as the values of the determined coefficients (see table. 1). Graphics that show the change of the value of the second standardized derivatives of functions, $\mu(k)$ and $P(k)$ are presented on figure. 7 .

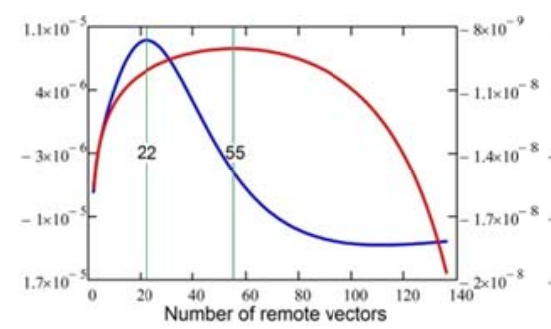

a)

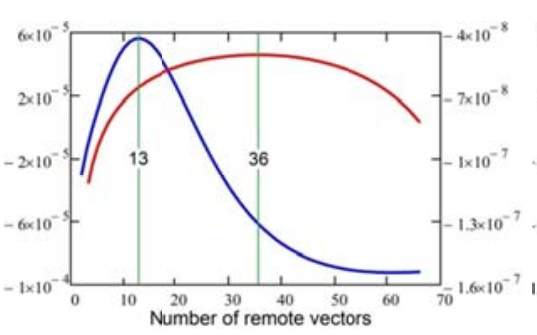

b)

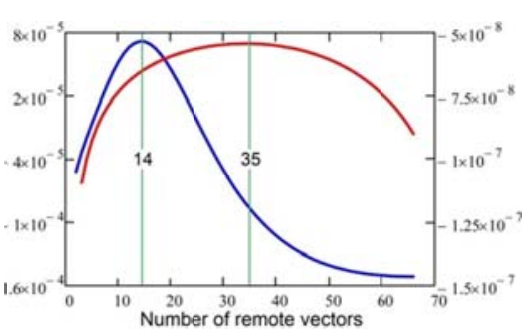

C)

Fig. 7. The change of the values of second normalized derived functions $\mu(k)$ and $P(k)$

(a) Dnieper HPP; b) Dniester HPP; c) Kanev HPP)

Analyzing the graphs (see Fig. 7) it can be noted that the groups optimal ratio are between 22 and 55 remote vectors for the Dnieper HPP network, between the 13th and 36th - for the Dniester HPP network and between the 14th and 34th for the Kanev HPP network.

Also, for the network presented the value of the entropy of geodesic networks $H_{m}(k)$ was calculated. Graphs of the values change of entropy of geodesic network is presented on figure 8 . 


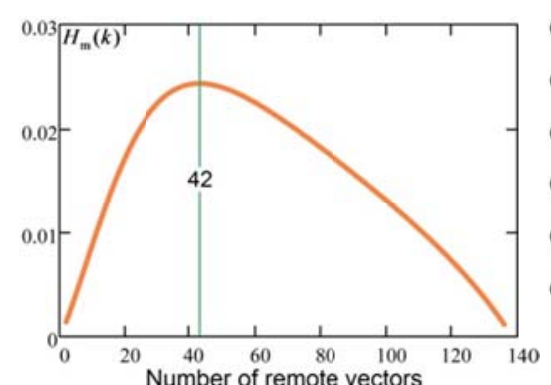

a)

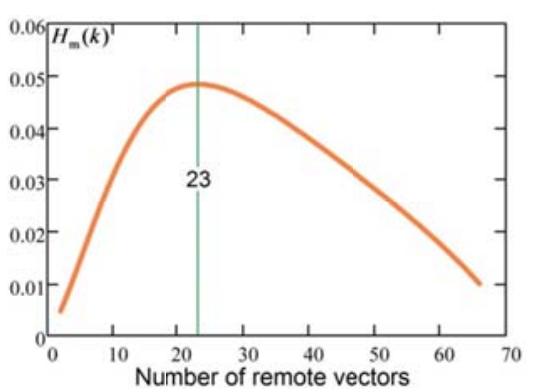

b)

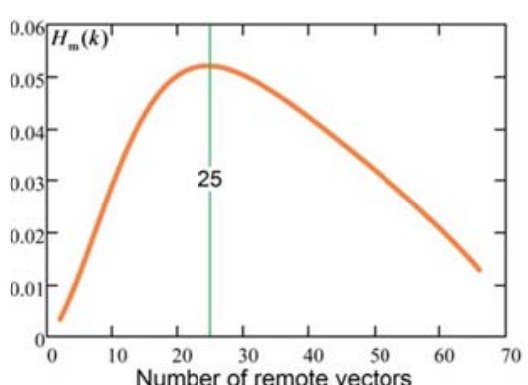

c)

Fig. 8. The change of entropy of geodesic networks $H_{m}(k)$

( a) Dnieper HPP; b) Dniester HPP; c) Kanev HPP)

According to the developed method for maximum of function $H_{m}(k)$ of networks provides the best value for accuracy and reliability. Therefore, analyzing the graphs (see Fig. 8) it can be concluded that by 42 remote vectors from the Dnieper HPP network, and 23 of the Dniester HPP network and 25 of the Kanev HPP network adjustment will give the best value for accuracy and reliability.

For the margins of the beginning and end of the remote vectors, as well as for the installed optimal margins and the margin of the best ratios values of mean square error (MSE) of determining the coordinates of points and average squared difference (ASD) coordinates were calculated from the genuine. Average coordinates of points obtained by the 10 days of observation were considered as genuine coordinates. The data is presented in table 2 .

Table 2. Values of MRSE and ASD for Dnieper, Dniester and Kanev HPP

\begin{tabular}{|c|c|c|c|c|c|c|c|c|}
\hline \multicolumn{3}{|c|}{ Dnieper HPP } & \multicolumn{3}{c|}{ Dniester HPP } & \multicolumn{3}{c|}{ Kanev HPP } \\
\hline $\begin{array}{c}\text { Number } \\
\text { of remote } \\
\text { vectors, items }\end{array}$ & $\begin{array}{c}\text { MSE, } \\
\mathrm{mm}\end{array}$ & $\begin{array}{c}\mathrm{ASD}, \\
\mathrm{mm}\end{array}$ & $\begin{array}{c}\text { Number } \\
\text { of remote } \\
\text { vectors, items }\end{array}$ & $\begin{array}{c}\text { MSE, } \\
\mathrm{mm}\end{array}$ & $\begin{array}{c}\mathrm{ASD}, \\
\mathrm{mm}\end{array}$ & $\begin{array}{c}\text { Number } \\
\text { of remote } \\
\text { vectors, items }\end{array}$ & $\begin{array}{c}\mathrm{MSE}, \\
\mathrm{mm}\end{array}$ & $\begin{array}{c}\mathrm{ASD}, \\
\mathrm{mm}\end{array}$ \\
\hline 0 & 4,9 & 3,7 & 0 & 5,2 & 4,3 & 0 & 5,4 & 4,5 \\
\hline 22 & 3,2 & 2,9 & 13 & 3,6 & 3,7 & 14 & 3,8 & 3,9 \\
\hline 42 & 2,1 & 1,5 & 23 & 2,7 & 2,9 & 25 & 2,9 & 3,2 \\
\hline 55 & 1,8 & 2,3 & 36 & 2,1 & 3,9 & 35 & 2,4 & 4.0 \\
\hline 90 & 1,3 & 3,4 & 60 & 1,6 & 5,7 & 60 & 1,8 & 4,8 \\
\hline
\end{tabular}

Analyzing the results presented in the table 2 it can be seen that removing of vectors with the maximum errors, MSE is improving, however ASD is improving at the beginning, and later starts to decline. The values ASD decrease occurs within an optimal balance of accuracy and reliability, and the smallest value ASD coincides with the maximal information content network.

Summing up it can be stated that the processing of the results of measurements made in the networks of the Dnieper, Dniester and Kanev HPP fully approves the developed method of posteriori optimization of measurement results of active geodesic monitoring networks taking into account the parameters of accuracy and reliability. Therefore, this method can be applied for optimization of any active geodetic monitoring networks with a large number of redundant measurements. 


\section{Conclusions}

The method of posteriori optimization of measurement results of active geodesic monitoring networks taking into account the parameters of accuracy and reliability is developed.

The boundaries of the optimal number of dimensions that has to be eliminated for maintaining optimal accuracy and reliability of results are set. Using entropic approach the limit of the best combination of accuracy and reliability of results is achieved.

The reliability of the developed method for processing of the results of measurements performed by automated systems of monitoring of the Dnieper, Dniester and Kanev HPP is experimentally verified.

Presented method can be applied for optimization of any active geodetic monitoring networks with a large number of redundant measurement

\section{Acknowledgement}

This publication was developed as a part of the research project UHE/T-DAM2-20/09 Execution of service activities for installation of permanent deformation monitoring system and joint GNSS and PSDM data processing entered between company Leica Geosystems $A G$ and Lviv Polytechnic National University funded by the Public Join Stock Company "Ukrhydroenergo".

\section{References}

Craenenbroeck, J.v. (2012). Engineering Structures. First International FIG Workshop, International Federation of Surveyors (FIG), Belgium, pp. 1-18.

Even-Tzur, G. (2002). GPS vector configuration design for monitoring deformation networks. Journal of Geodesy, 76(8), pp. 455-461. doi: 10.1007/s00190-0020274-5

Knight, N. L., Wang, J., \& Rizos, C. (2010). Generalised measures of reliability for multiple outliers. Journal of Geodesy, 84(10), pp. 625-635. doi:10.1007/s00190010-0392-4

Prószyński, W. (2010). Another approach to reliability measures for systems with correlated observations. Journal of Geodesy, 84(9), pp. 547-556. doi: 10.1007/s00190-010-0394-2

Rizos, C., Craenenbroeck, J.v., \& Liu, V. (2010). Advances in GNSS-RTK for Structural Monitoring in Regions of High lonospheric Activity. Deformation Measurement of Structures Using GNSS, FIG Congress 2010, held 11-16 April, 2010 in Sydney, Australia, pp. 1-13.

Rodionova, Yu.V. (2006). Optimizatsiya planovoy geodezicheskoy seti goroda N po kriteriyu geometricheskoy nadezhnosti [Optimization of planned and geodetic network of the city $\mathrm{N}$ by geometric reliability]. Vestn. SGGA [Bulletin of SGGA], 11, pp. 125-129. 
Rodionova, Yu.V., \& Dyakov, B.N. (2004). O povyshenii nadezhnosti nekotorykh geodezicheskikh postroeniy [About improving the reliability of some geodesic constructions]. Geoprofi, 4, pp. 48-50.

Stempfhuber W., \& Alberding, J. (2012). Geodätische Monitoringsysteme mit RTK Low-Cost-GNSS. Allgemeine Vermessungs-Nachrichten: AVN, 119(4), pp. 132139.

Tretyak, K.R. (1993). Uzaghaljnenyj kryterij optymizaciji gheodezychnykh merezh [Generalized criterion of optimization of geodetic networks]. Gheodezija, kartoghrafija i aerofotoznimannja [Geodesy, Cartography and Aerial Photography], 55, pp. 93-102.

Tretyak, K.R. (2003). Aposteriorna optymizacija gheodezychnykh merezh [Posteriori optimization of geodetic networks]. Zb.: «Suchasni dosjaghnennja gheodezychnoji nauky ta vyrobnyctva» [Journal: "Modern geodesic advances of science and industry»], pp. 127-141.

Tretyak, K.R., \& Savchyn, I.R. (2013a). Rozroblennja metodyky rozrakhunku nadijnosti aktyvnykh monitorynghovykh merezh [Reserch of reliability of active geodetic network for deformation monitoring]. Visnyk gheodeziji ta kartoghrafiji [Bulletin of Geodesy and Cartography], 1(82), pp. 5-10.

Tretyak, K.R., \& Savchyn, I.R. (2013b). Do pytannja nadijnosti aktyvnykh monitorynghovykh merezh [On the issue of reliability of active geodetic monitoring networks]. Gheodezija kartoghrafija i aerofotoznimannja [Geodesy, Cartography and Aerial Photography], 77, pp. 122-126.

\footnotetext{
Authors:

Kornyliy Tretyak ${ }^{1)}$, Prof. Dr.habil., kornel@Ip.edu.ua Igor Savchyn ${ }^{1)}$, Ph.D. student, savchyn.ih@gmail.com ${ }^{1)}$ National university Lviv polytechnic. Institute of Geodesy. 79013 Lviv, 12 Bandera street, Ukraine.
} 